Souza, C.S.; Braghini, C.R.; Araújo, L.F. Espaços de diálogo na comunidade para o Ecoturismo: a Ilha Mem de Sá, Itaporanga D'ajuda (SE). Revista Brasileira de Ecoturismo, São Paulo, v.3, n.2, 2010, pp.235-248.

\title{
Espaços de diálogo na comunidade para o Ecoturismo: a Ilha Mem de Sá, Itaporanga D'ajuda (SE)
}

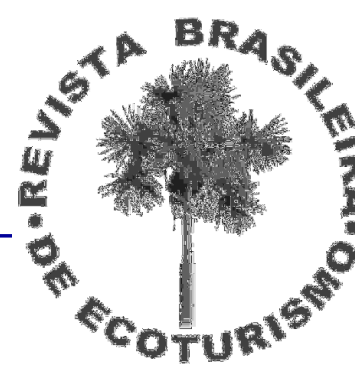

\section{Cleberton Santos Souza, Claudio Roberto Braghini, Layslene Ferreira de Araújo}

\begin{abstract}
RESUMO
O ecoturismo pode ser visto como uma viagem à natureza que almeja contribuir com a conservação ambiental e o desenvolvimento das comunidades receptoras. Em seu desenvolvimento é necessário a integração dos interesses possibilitando espaços de diálogo com participação direta das populações locais. Este estudo mostrou a importância dos espaços de diálogos na comunidade da Ilha Mem de Sá, para que ela se aproprie do ecoturismo como forma de conservação ambiental e fonte de renda. Nesta perspectiva o Projeto Re-Conhecer Pedra Bonita gerou um espaço de discussão sobre turismo no município de Itaporanga D'Ajuda, que ainda não apresenta roteiros turísticos. Para tal, utilizou-se da técnica de Diagnóstico Rural Participativo (DRP) denominada mapa falado, como ferramenta para estimular o diálogo, que possibilitou aos moradores identificar potenciais atrativos turísticos da região. A contribuição comunitária adquirida pelo diálogo permitiu gerar e executar o Roteiro Pedra Bonita. A participação da população na execução do roteiro estabeleceu novo espaço de diálogo, aprimorando a escolha dos potenciais atrativos e o próprio roteiro. Os participantes refletiram sobre os ambientes e aspectos culturais de seu território.
\end{abstract}

PALAVRAS-CHAVE: Ecoturismo, Participação Comunitária, Dialogicidade (Espaços de Diálogo)

Spaces's dialogue in the community for Ecotourism: the Mem de Sá Island, Itaporanga D'Ajuda - Sergipe, Brazil

\begin{abstract}
Ecotourism can be seen as a trip to nature that has a goal to contribute to environmental conservation and as well as the receptive communities' development. For the ecotourism's development it is necessary to integrate different interests making the spaces of dialogue possible in wich there is the direct participation of the local communities. This study aimed to show the importance of the spaces of dialogues at Mem de Sá Island community, so that they could appropriate the ecotourism as a form of environmental conservation and economic source. The Re-Conhecer Pedra Bonita Project was implemented in the community and provides a space for discussion about tourism in the city of Itaporanga D' Ajuda, that doesn't have any touristic route. This way, the DRP technique, called said map, was used as a main tool to encourage the dialogue. That technique alowed to the inhabitants to identify attractive touristic potential of the area. The community contribution provided by the dialogue allowed to generate and to execute the Pedra Bonita touristic route. The participation of the population in the execution of the route established new space of dialogue, improving the choice of the attractive touristic potentials and the touristic rout as well. The inhabitants were able to reflect on environments and cultural aspects of its habitat.
\end{abstract}

KEYWORDS: Ecotourism, Community Participation, Dialogicity 
Espaços de diálogo na comunidade para o Ecoturismo: a llha Mem de Sá, Itaporanga D’ajuda (SE).

\section{Introdução}

O ser humano como um dos principais agentes transformadores da natureza, tem apresentado grande interesse de estar em ambientes naturais e assim contribuir com sua conservação, fortalecendo a ideia de ligação entre o homem e a natureza. Observou-se, a partir das últimas décadas do século $X X$, um crescimento significativo no número de visitas a áreas naturais em escala mundial (CEBALLOS-LASCURÁIN, 2002; OMT, 2003). Assim, esse crescimento evidenciaria possivelmente que, "tal como necessita-se da arte, precisa-se do contato com a natureza, a fonte da vida" (MENDONÇA; NEIMAN, 2002, p.158).

O ecoturismo como fenômeno mundial está associado a esse maior interesse por visitar ambientes naturais, mas com a preocupação quanto aos danos ecológicos que ele pode provocar (WESTERN, 2002). O ecoturismo emergiu como possibilidade de conservar ambientes e ao mesmo tempo gerar emprego e desenvolvimento local (WESTERN, 2002).

O ecoturismo tornou-se por um lado uma viagem voltada à natureza de pequena escala e por outro se estabeleceu como um "conjunto de princípios aplicáveis a qualquer tipo de turismo que se relacione com a natureza” (WESTERN, 2002, p. 21).

Nessa perspectiva o ecoturismo englobaria viagens que proporcionam ligação entre o homem e a natureza, mas também promovem recursos para a conservação do meio ambiente e o desenvolvimento das comunidades receptoras, conforme o conceito trazido pela The Ecotourism Society que diz "ecoturismo é a visita responsável a áreas naturais visando preservar o meio ambiente e o bem-estar das populações locais" (BOO, 2002).

Nota-se nesse conceito a relação intrínseca que o ecoturismo possui com as comunidades locais, sendo que o bem-estar destas populações não pode ser resumido apenas em torná-las atrativos aos visitantes por meio de seu patrimônio cultural, cabe nesta relação um parâmetro fundamental, que os projetos de ecoturismo objetivem "maximizar o impacto socioeconômico e ambiental positivo para as comunidades locais e minimizar o impacto negativo" (BRANDON, 2002, p.226).

Para que este parâmetro não se torne uma falácia é de extrema importância que haja o "empenho e comprometimento político dos governantes" e que ocorra "a integração das necessidades e preferências locais no processo de planejamento" (BRANDON, 2002, p.225-226). Neste aspecto as preferências locais não podem ser substituídas por interesses mercadológicos, mas devem ser identificadas com a participação daqueles que vivenciam o ambiente, os moradores.

A participação da comunidade no processo de desenvolvimento do ecoturismo foi evidenciada em 1982, no tocante a áreas protegidas, no Congresso Mundial sobre Parques Nacionais. De acordo com McNeely e Miller apud Brandon (2002, p.226) "a proposta de incluir a população local no planejamento e administração de parques foi aceita com entusiasmo por conservacionistas e administradores de áreas protegidas". Assim deve existir um diálogo durante o desenvolvimento da atividade ecoturística em ambientes naturais. 
Para que uma comunidade participe do processo de desenvolvimento do ecoturismo é preciso planejamento e escolha de ferramentas de diálogo que permitam gerar reflexão e discussão sobre a própria realidade, de forma que a comunidade se torne capaz de transformá-la.

O ecoturismo pressupõe assim uma busca de ferramentas de diálogo para que a comunidade participe do processo, que implica reflexão e discussão sobre sua realidade, de forma que se torne capaz de transformá-la.

A educação ambiental insere-se nesse processo, na medida em que se concebe que educar significa "saber ler o mundo", estabelecendo um movimento de conhecer para transformar e ao transformar, conhecer. A educação ambiental envolve metodologias participativas e dialógicas e tem ainda um sentido político, pois visa à emancipação dos sujeitos (LOUREIRO, 2004).

Segundo Loureiro (2004, p.18) "participar é compartilhar poder, respeitar o outro, assegurar igualdade na decisão, propiciar acesso justo aos bens socialmente produzidos, de modo a garantir a todos a possibilidade de fazer a sua história no planeta, de nos realizarmos em comunhão".

De acordo com o enfoque acima, o Instituto Federal de Sergipe (IFS), através do Curso Superior de Tecnologia em Gestão de Turismo aproximou-se da comunidade da llha Mem de Sá, no município de Itaporanga D’Ajuda. A Ilha Mem de Sá tem despertado o interesse de visitantes que apreciam seus ambientes naturais e os aspectos culturais, bem como, de pesquisadores que buscam desenvolver estudos em diversas áreas do conhecimento. Essa ilha situa-se próxima ao Campo Experimental de Itaporanga - CEI, também denominado de Reserva do Caju, área administrada pela Empresa Brasileira de Pesquisa Agropecuária - Embrapa Tabuleiros Costeiros.

O IFS iniciou uma parceria de caráter técnico e científica com a Embrapa Tabuleiros Costeiros, visando identificar o potencial para o desenvolvimento do ecoturismo na Reserva do Caju. Posteriormente, surgiu o Macroprograma da Embrapa denominado 'Desenvolvimento participativo da comunidade Mem de Sá'. O macroprograma propõe o ecoturismo como uma atividade que "fortalecerá a consciência ambiental individual e coletiva [...] e o incremento da renda familiar" (CURADO, 2007).

A resposta do IFS foi gerar o projeto 'Estudo do desenvolvimento do ecoturismo na llha Mem de Sá e na Reserva do Caju' permitindo diálogo entre as instituições e integração de esforços, incorporando-se às ações de pesquisa do macroprograma, como também aos diálogos entre Embrapa e Associação de Moradores da Ilha Mem de Sá.

O projeto Re-conhecer Pedra Bonita direcionado à comunidade da llha Mem de Sá foi uma iniciativa do IFS, dentro da III Semana de Extensão do Curso de Gestão em Turismo do IFS. A intenção foi aproximar-se da comunidade da llha Mem de Sá, sem interferir ou confundir com ações da Embrapa, visto que a ação extensionista seria de curta duração e não estaria prevista no projeto de parceria. No entanto, discentes do curso mostrariam afinidade ao tipo de iniciativa e poderiam compor a equipe para a continuidade no projeto de parceria. 
A proposta escolhida foi uma atividade à comunidade Mem de Sá na sede do município de Itaporanga D'Ajuda, que não discutisse a realidade da llha, de forma direta. O desafio inicial do projeto de extensão foi encontrar uma resposta à seguinte questão: como oferecer à comunidade um roteiro turístico na sede de seu município, pois vivenciavam a cidade cotidianamente?

Este estudo visou mostrar a importância dos espaços de diálogos na comunidade da Ilha Mem de Sá, a partir do projeto de extensão Re-Conhecer Pedra Bonita, dentro da III Semana de Extensão do Curso de Gestão em Turismo do IFS, em um processo de desenvolvimento do ecoturismo como forma de conservação ambiental e geração de renda.

\section{Caracterização da Área}

A Ilha Mem de Sá é uma ilha fluvial do Rio Paruí, afluente do Rio Vaza-Barris e localiza-se em $37^{\circ} 12^{\prime} 59^{\prime \prime}$ W e $11^{\circ} 06^{\prime} 07^{\prime \prime} \mathrm{S}$, no município de Itaporanga D'Ajuda, $\mathrm{SE}$, distanciando $23 \mathrm{~km}$ da sede municipal e $53 \mathrm{~km}$ da capital sergipana. O acesso a esta localidade pode ser realizado de duas formas: a primeira, através da BR-101 que liga Aracaju a Itaporanga que dá acesso a SE-204, também denominada de Rodovia Humberto Mandarino, interligando a sede municipal ao Assentamento Darci Ribeiro, onde é realizada uma travessia fluvial no Rio Paruí até a ilha; a segunda, parte da capital até o Povoado Mosqueiro onde é feita a travessia de balsa pelo Rio Vaza-Barris, trajeto que em breve será feito através da Ponte Jornalista Joel Silveira, chegando a SE-100, no Povoado Caueira em Itaporanga seguindo pela SE-204, destinando-se ao Assentamento, realizando a partir deste local a travessia fluvial.

No entorno da ilha encontra-se o CEI - Reserva do Caju, margeado pelos rios Paruí e Vaza-Barris, localizado em $37^{\circ} 11^{\prime} 4^{\prime \prime}$ W e $11^{\circ} 6^{\prime}$ 7" S (Figura 1). O acesso pode ser realizado pela SE-100, que partindo de Aracaju fica a $28 \mathrm{Km}$ de distância. Caso a partida seja de Itaporanga D'Ajuda o percurso é de $41 \mathrm{~km}$, através da SE-204, em seguida pela SE-100 no sentido Caueira-Aracaju.

Trata-se de região estuarina, caracterizada por ecossistemas de baixada litorânea tendo, Mata Atlântica, restinga e mangue, o que historicamente proporcionou aos moradores da llha um ambiente para captura de caranguejo e outros crustáceos, além da pesca, da caça e do lazer. Esse aspecto mostrou uma profunda interação dos moradores com os ecossistemas locais.

Aproximadamente 75 famílias vivem nesta localidade e dependem da pesca artesanal, que constitui a principal atividade econômica da comunidade, além do cultivo de mandioca e macaxeira, e o aproveitamento do coco.

Um aspecto cultural regional relevante é o samba de coco, "dança popular nordestina, cantado em coro e refrão que responde aos versos do "tirador de coco", chamado também "coqueiro"' (SILVA e CARDOSO, p.7). O grupo que é denominado de Samba de Coco da llha de Mem de Sá é uma das atrações dos festejos juninos de Sergipe, apresentando-se em diversas cidades do Estado incluindo o Arraiá do Povo em Aracaju, tradicional festa junina, conhecida nacionalmente. 
Souza, C.S.; Braghini, C.R.; Araújo, L.F.

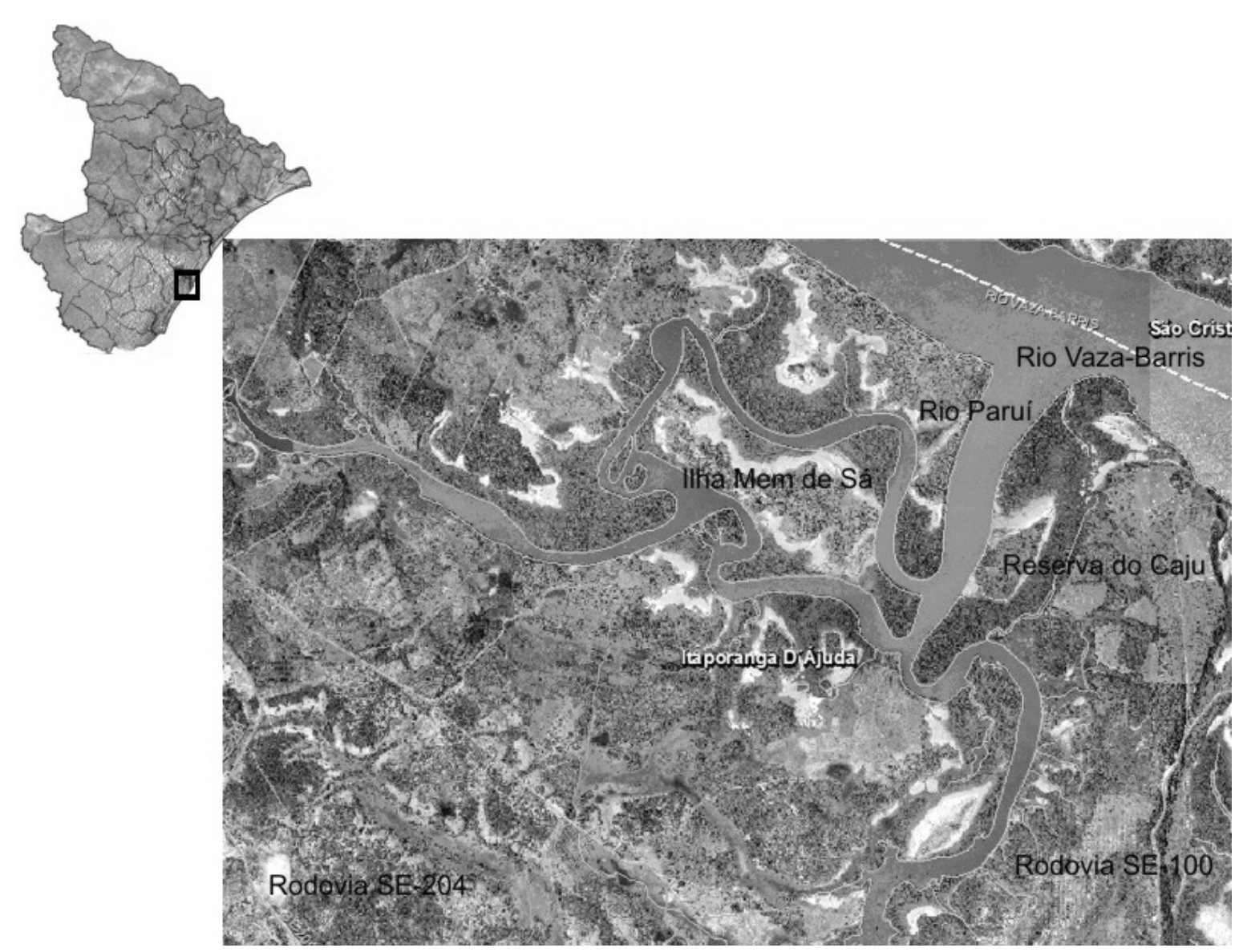

Figura 1 - Localização da llha Mem de Sá e Reserva do Caju. Fonte: Veja Sergipe - Visualizador da Base Cartográfica dos Municípios Litorâneos, adaptado (SEPLAN-SE/SUPES/GIGEC, 2008)

Em dezembro os moradores da llha promovem comemorações à Santa Luzia, padroeira da localidade. Neste período os moradores realizam eventos de cunho religioso para celebrar sua padroeira. No mesmo período é realizada a Festa do Caranguejo, simbolizando a pesca como uma das principais atividades econômicas da população, evento que conta com a participação de bandas musicais de localidades próximas, como também dos grupos folclóricos existentes na llha.

Na Reserva do Caju são desenvolvidas pesquisas de práticas agroecológicas, de manejo sustentável do uso do solo em ecossistemas agrícolas. Há bancos de germoplasma de plantas tropicais, como o coco do betume e a mangaba.

A missão desse campo experimental é tornar-se um centro de referência em Educação Ambiental. Além disso, a Embrapa atualmente destinou 860 ha da área da reserva para a implantação de uma Reserva Particular do Patrimônio Natural (RPPN), que atualmente está em tramitação no IBAMA/SE através do processo de número 0202800098402-17 (EMBRAPA, 2009).

Na região algumas pressões têm se intensificado como a expansão de lotea- 
Espaços de diálogo na comunidade para o Ecoturismo: a llha Mem de Sá, Itaporanga D’ajuda (SE).

mentos imobiliários, o turismo convencional insustentável, a carcinicultura e a caça da fauna existente. Daí a razão de se agir com certa urgência e se propor alternativas que beneficiam as riquezas sócio-culturais e ambientais da região.

\section{O Projeto Re-conhecer Pedra Bonita}

O projeto Re-conhecer Pedra Bonita proporcionou a quinze moradores, uma vivência turística dentro do seu município. Em seu desenvolvimento foram executadas três fases: a identificação dos possíveis atrativos, a execução de um roteiro e avaliação das etapas.

Inicialmente os acadêmicos elaboraram um roteiro prévio a partir da catalogação de informações referentes aos aspectos geográficos e histórico-culturais da sede municipal e da Reserva do Caju, com base em referências bibliográficas, entrevistas aplicadas a moradores antigos da cidade e representantes do poder público, além da observação in loco.

Paralelamente, ocorreria um contato prévio entre acadêmicos do IFS e representantes da comunidade Mem de Sá. A partir deste, seria combinado um encontro com a equipe do projeto de extensão do IFS para esclarecer a proposta a um grupo de moradores da llha.

Essa fase serviria como momento de esclarecimento e também de sensibilização e para tal, escolheu-se uma oficina de Diagnóstico Rural Participativo (DRP), que se utiliza de diagramas que possuem o papel "de "ferramentas de diálogo que favorecem a interpretação coletiva da realidade em suas várias dimensões" (FARIA; FERREIRA, 2006, p.12).

A técnica de DRP escolhida foi o mapa falado que tem como características marcantes a possibilidade de gerar uma visão espacial do local, auxilia na obtenção de informações sobre a localidade, de forma exploratória, além de permitir obter uma imagem geral da realidade (FARIA; FERREIRA, 2006).

Nesse encontro seria inicialmente apresentado à comunidade o papel da Instituição (IFS) e algumas considerações sobre turismo, ecoturismo, Ilha Mem de Sá, Itaporanga D'Ajuda e a semana de extensão que consiste em "um trabalho realizado pelo corpo discente do curso de Gestão de Turismo, com a finalidade de desenvolver na prática o aprendizado técnico e teórico desenvolvido em sala" (BRAGHINI; PICANÇO, 2009).

Durante o diálogo buscar-se-ia identificar a percepção dos moradores quanto à potencialidade turística da sede do seu município: Itaporanga D’Ajuda-SE.

Para a elaboração dos mapas a proposta foi dividir os participantes em dois grupos e fornecer materiais como cartolinas brancas e pincéis atômicos. Dois acadêmicos atuariam como facilitadores estimulando o diálogo entre os participantes em cada grupo, que representariam graficamente os elementos de sua cidade. Outros acadêmicos teriam o papel de registrar as falas e elementos que julgassem relevantes.

Após o término dos mapas, um representante de cada grupo apresentaria os 
pontos mais importantes da sede do seu município, destacando os possíveis atrativos turísticos, elementos culturais, de infra-estrutura e equipamentos.

Os mapas seriam fotografados para posterior análise, conjuntamente com os registros, bem como, forneceria subsídio ao grupo responsável pela elaboração do roteiro prévio.

A avaliação do processo seria tarefa da equipe do IFS, que incluiria discussões após a confecção do mapa falado, as falas e registros durante e após a execução do roteiro Pedra Bonita, considerando-se a opinião e sugestões dos participantes, além da análise entre a equipe do IFS ao final da atividade, que permitiria gerar um relatório.

\section{O Espaço de Diálogo e o Mapa Falado}

A equipe do IFS dividiu-se em dois grupos, sendo um grupo responsável por construir o roteiro prévio na sede de Itaporanga D'Ajuda e o outro, articular com a comunidade Mem de Sá. O segundo grupo esteve mais envolvido com o espaço de diálogo prévio, enquanto que o primeiro permitiria diálogo ao longo do roteiro proposto.

O contato prévio com representante dos moradores da llha Mem de Sá permitiu legitimar a presença da equipe do IFS, bem como articulou encontro de 18 de junho de 2009, para a fase de sensibilização e esclarecimento da proposta do roteiro turístico Pedra Bonita.

No dia 18 de junho de 2009 ocorreu o encontro entre seis acadêmicos, um professor do Instituto Federal de Educação, Ciência e Tecnologia de Sergipe (IFS) e um grupo de 16 moradores da llha Mem de Sá, em que se aplicou oficina de DRP, como principal ferramenta para promover o diálogo na comunidade, a partir da técnica de mapa falado.

Os participantes foram subdivididos em dois grupos e instigados a identificar atrativos turísticos da cidade, além de empreendimentos que ofereçam serviços ao público-alvo do turismo, e representá-los graficamente num mapa construído coletivamente.

Inicialmente, observou-se a desconfiança e descrença de alguns moradores que questionaram, afirmando que vão diariamente à cidade de Itaporanga D'Ajuda e nunca viram "nada de turismo lá". Por outro lado, reconheceram existir visitação turística na ilha caracterizada por pesquisadores da Embrapa Tabuleiros Costeiros e instituições de ensino e pesquisa que desenvolvem ações nesta localidade, como também os visitantes dos festejos realizados na llha.

Essa afirmação de que não haveria potencial turístico era a visão inicial dos moradores da llha Mem de Sá para com a atividade turística, sendo o ponto que norteou as questões para o desenvolvimento das ações propostas.

No grupo 1 os acadêmicos estimularam a construção do mapa falado tendo o diálogo como base para se debater o tema proposto. Aos poucos os moradores per- 
deram a inibição e começaram a participar e estabelecer uma reflexão conjunta. Assim esta atividade prática e reflexiva levou os moradores à questão-chave, o que se caracterizaria atrativo turístico na da cidade?

Dentro dos grupos formados, o diálogo foi se intensificando na medida em que os moradores debatiam sobre o potencial turístico dos ambientes e empreendimentos identificados na cidade, como, os casarios antigos, a rodoviária, a pousada, o ginásio de esportes, entre outros. Debateram entre si e refletiram sobre a importância destes espaços para o turismo. Ao chegarem a um consenso, passavam a representá-los no mapa.

Observou-se que no mapa falado do grupo 1 (Figura 2), as casas, prédios públicos e igrejas eram destacadas por suas características arquitetônicas desenvolvidas no período de colonização desta região, sendo que um dos principais elementos que despertou a atenção deste grupo durante os debates. A BR-101 foi identificada como a principal via de acesso à cidade, outra referência foi a praça onde os principais eventos são realizados, evidenciando a relevância das festas juninas e a atratividade de visitantes de outros municípios durante o período destes e outros festejos. Os equipamentos de apoio ao turismo como, pousada, ginásio e rodoviária, despertaram a atenção dos moradores e constituem-se em importantes pontos do debate neste grupo, por sua relevância para a atividade turística em debate.

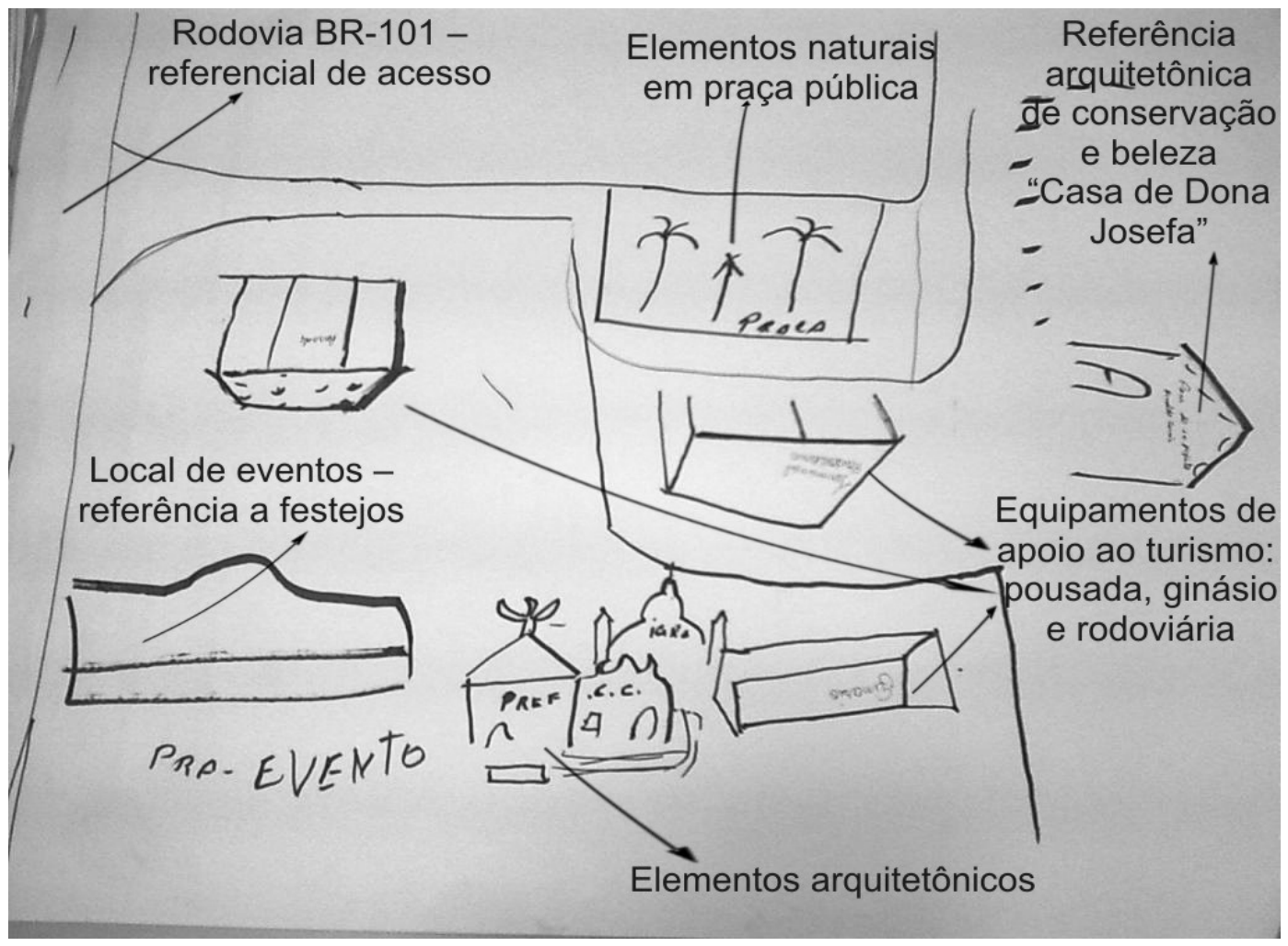

Figura 2 - Mapa falado da cidade de Itaporanga D'Ajuda do grupo 1.

Foto: Cleberton Souza, 2009, adaptado. 
No grupo 2 o processo de desinibição foi semelhante, mas a preocupação inicial dos moradores foi representar a distribuição das diversas construções, os acessos, equipamentos e posteriormente, reconhecer o que seria atrativo turístico (Figura 3).

Assim, definido a distribuição dos elementos no mapa a discussão se dirigiu para a existência de atrativos na cidade, destacando-se a praça em que ocorre o forró e a bica, local que atualmente encontra-se fechado. A seguir, foram estimulados a indicarem os meios de hospedagem, restaurantes e bares, que de acordo com a opinião deles seriam mais indicados para turistas. Evidenciou-se registrado no mapa a existência de infraestrutura de apoio, tais como delegacia, farmácia, mercado, rodoviária, posto de gasolina e mototáxi, como também dos aspectos naturais existentes tendo esse grupo focado em seu desenho o Rio Vaza-Barris que além de margear a Reserva do Caju e llha Mem de Sá, banha a cidade de Itaporanga D'Ajuda.

Durante o processo de construção do mapa surgiram aspectos relativos aos nomes populares de determinados espaços urbanos, reforçando a importância do diálogo para reconhecer e valorizar a cultura local pela atividade turística.

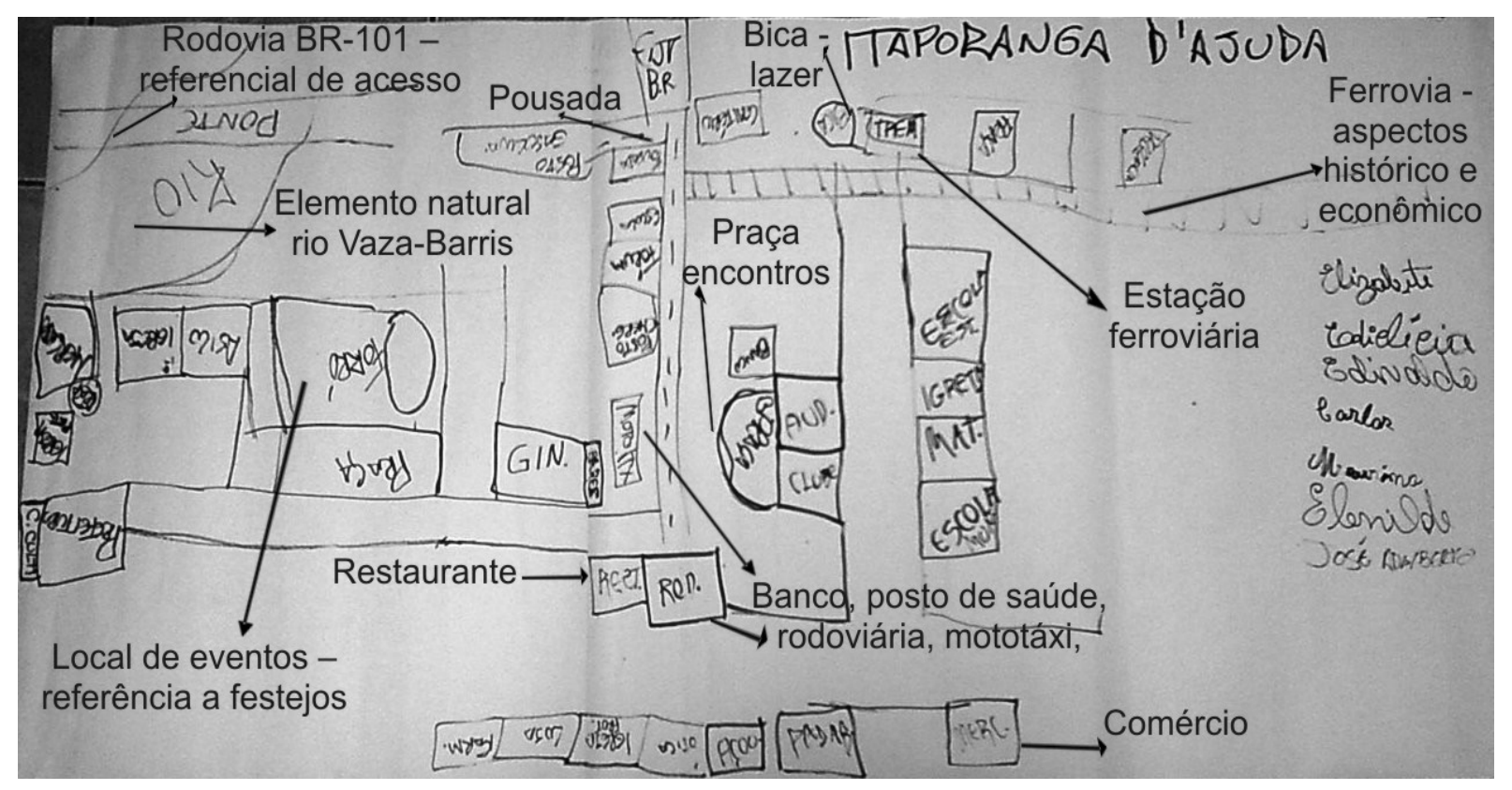

Figura 3 - Mapa falado da cidade de Itaporanga D'ajuda do grupo 2.

Foto: Cleberton Souza, 2009, adaptado.

$\mathrm{Na}$ última etapa da oficina cada grupo apresentou seu mapa, destacando os pontos referenciados orientando os trajetos para se chegar a eles (Figura 4). Nesse momento os grupos determinaram até dois moradores para explicar como se configurou a distribuição dos elementos identificados e registrados, como também, sua importância para a atividade turística. 


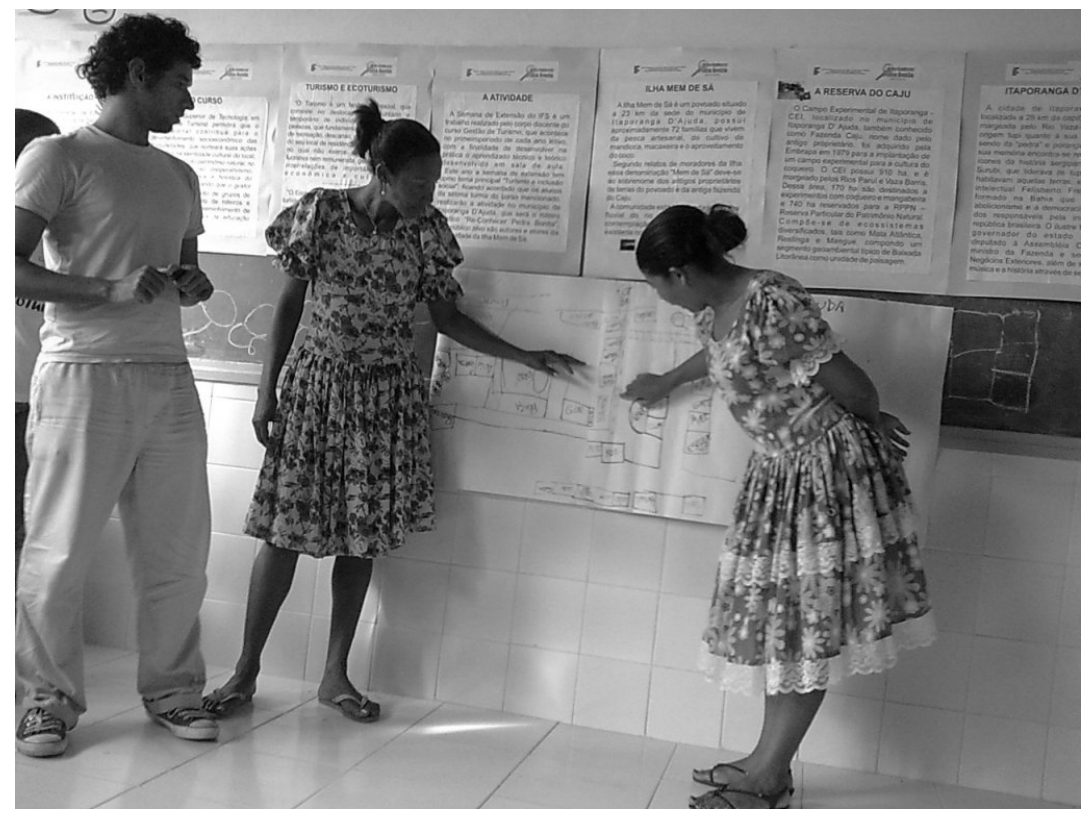

Figura 4 - Apresentação do mapa falado do grupo 2. Foto: Cleberton Souza, 2009.

Ao se comparar os mapas observou-se que ambos continham locais em comum, evidenciando que os moradores, apesar do seu pouco conhecimento sobre o turismo, compreendem o que os turistas gostam de conhecer.

O momento de exposição permitiu a comparação e a discussão sobre as propostas definidas pelos moradores, além de estimular a expressão e a escuta de diferentes pontos de vista valorizando o diálogo e a participação comunitária no processo de gestão de destinos turísticos.

\section{O Roteiro Pedra Bonita e sua Execução}

Os acadêmicos do IFS elaboraram um roteiro prévio dentro da cidade de Itaporanga D'Ajuda que foi complementado com o resultado do diálogo gerado no mapa falado. Desta forma o roteiro foi re-elaborado e executado em 03 de julho de 2009 com o apoio e participação da Embrapa Tabuleiros Costeiros, da Prefeitura Municipal de Itaporanga D'Ajuda e Viver Turismo, este representando as agências de viagens do trade turístico sergipano.

Organizaram-se duas equipes de condutores, sendo a primeira incumbida de realizar a travessia fluvial da llha Mem de Sá à Reserva do Caju, de 15 moradores, enquanto a segunda ficou responsável pela logística nas cidades de Aracaju e Itaporanga D’Ajuda no tocante ao traslado dos participantes destas cidades à Reserva do Caju, ponto de partida do roteiro. Houve encontro das equipes e todos os participantes do roteiro com dinâmicas de integração no ambiente natural da Reserva.

No percurso à cidade de Itaporanga foi abordada a relação dos ecossistemas da região de baixada litorânea, como, manguezal, Mata Atlântica e restinga, e a relação das comunidades do entorno com estes ambientes.

Durante o roteiro urbano os participantes puderam apreciar a história da cidade desde 
sua origem, a denominação antiga, Irapiranga, e seus monumentos como, igrejas, estação ferroviária e elementos arquitetônicos (Figura 5). Tal abordagem permitiu se discutir aspectos econômicos, que incluem a importância da ferrovia e do mercado municipal.

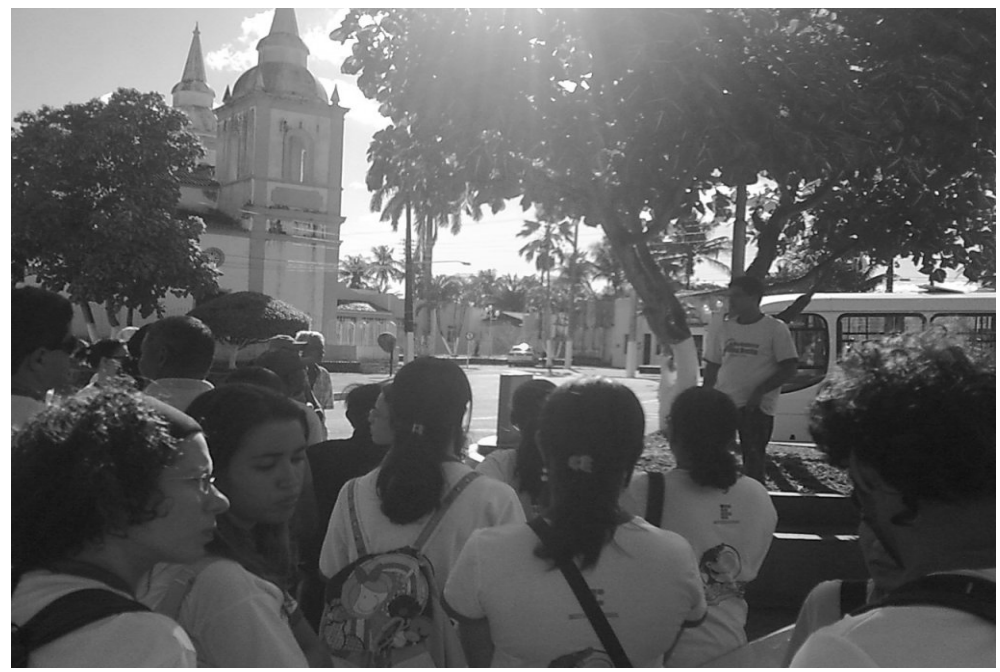

Figura 5 - Execução do roteiro Pedra Bonita, ao fundo Igreja Matriz de Itaporanga D’Ajuda. Foto: Cleberton Souza, 2009.

O enfoque cultural do roteiro foi abordado, como patrimônio imaterial através das manifestações religiosas e folclóricas existentes no município. Exemplo vivo foi a apresentação da Banda de Pífanos que realizou uma tocada para os participantes do roteiro na Casa de Cultura finalizando o Roteiro Pedra Bonita.

\section{A Avaliação do Roteiro}

No encerramento das atividades foi aberto mais um espaço de diálogo, em que acadêmicos, moradores e representantes do trade turístico sergipano e da Prefeitura de Itaporanga D’Ajuda opinaram, avaliaram, criticaram e elogiaram os aspectos relevantes do roteiro.

A Secretaria de Cultura do município sugeriu incrementar o roteiro com informações históricas desse território com um nível aprofundado, enquanto a agência de viagens Viver Turismo interessou-se em desenvolver um novo roteiro com base no elaborado pelo corpo acadêmico do IFS e a comunidade da llha Mem de Sá.

Os moradores que participaram desde a elaboração do roteiro até sua execução surpreenderam-se com a riqueza histórico-cultural de sua cidade, ao vivenciarem os ambientes com um novo olhar com enfoque turístico. Alguns citaram que não conheciam a história em torno de cada monumento e empreendimento da localidade e suscitaram a ideia de desenvolverem roteiro turístico na ilha.

O contato presencial da comunidade da ilha Mem de Sá com a Casa da Cultura gerou discussão sobre o desenvolvimento do artesanato com coco, sendo esta técnica de domínio de alguns habitantes locais, que estavam no espaço de diálogo e sugeriram que seus produtos artesanais fossem comercializados em futuros roteiros que possam ser implantados na Ilha. 
Dessa forma o espaço de diálogo gerou reflexão e aprendizado quanto ao que se caracterizaria atrativo na cidade de Itaporanga D'Ajuda e na llha Mem de Sá, sendo o artesanato com coco percebido como uma fonte de renda e atratividade para o ecoturismo na ilha.

No IFS a avaliação do processo foi feita entre a equipe, dias depois, destacando-se os aspectos positivos, negativos e a melhorar. Desse diálogo ressaltaram-se os seguintes aspectos, além daqueles levantados anteriormente:

- A importância da iniciativa dos acadêmicos em organizar e realizar a atividade em curto espaço de tempo, com poucos recursos.

- Destacou-se que os discentes, atuantes como se fossem guias durante a vivência do roteiro, deveriam ter simulado mais vezes sua apresentação o que permitiria gerar maior interação com os participantes, ampliando os espaços de troca de informações.

- Os registros do processo poderiam ser trabalhados de forma mais eficaz, pois informações relevantes não foram anotadas, bem como houve extravio de alguns registros.

- Reconheceu-se a dificuldade de realizar atividades no ônibus, que fora cedido pela prefeitura de Itaporanga D'Ajuda, pois se tratava de ônibus escolar e não possuía microfone, portanto, não estaria preparado para esse tipo de atividade.

- A equipe observou a necessidade de equalizar os tempos em cada parada, visto que o roteiro terminara antes do período previsto.

- Por fim, alguns participantes que não conheciam a cidade reconheceram que a existência de um mapa poderia auxiliar na localização, durante o roteiro.

De forma geral, segundo os orientadores foi positiva a articulação que os acadêmicos do IFS fizeram entre si, com a Prefeitura de Itaporanga D'Ajuda, Embrapa e comunidade Mem de Sá para efetivação das atividades.

\section{Conclusão}

O ecoturismo, como deve ser concebido em sua prática implica planejamento e esclarecimento das ações, de forma a contemplar os princípios de conservação ambiental, participação comunitária e geração de renda.

A participação da comunidade ao longo do processo de desenvolvimento do ecoturismo é essencial para a auto-gestão da própria atividade. As ações devem ser identificadas participativamente de forma que sejam contempladas as várias expectativas dos diversos segmentos sociais.

A própria comunidade receptora necessita compreender o ecoturismo e tal processo, por vezes depende de informações e sensibilização, que podem ser efetuados por meio dos diálogos. Nesse contexto os espaços de diálogo possuem um caráter educativo proporcionando aos indivíduos o movimento de conhecer para transformar e ao transformar, conhecer. 
As expressões de satisfação e surpresa dos participantes, pelo fato de perceberem que Itaporanga D'Ajuda pode se constituir um atrativo turístico, além da relação feita por alguns moradores entre a vivência e as possibilidades de aplicação na própria llha, mostraram que a ferramenta de DRP mapa falado e a vivência do roteiro foram adequadas e permitiram aproximar a comunidade da equipe do IFS.

A proposta, apesar de ter sido uma iniciativa do IFS, desenvolveu-se de maneira a respeitar a comunidade, desde a consulta prévia, durante o processo de sensibilização e na avaliação da vivência, proporcionando espaços de diálogo. A atividade, apesar de curta, reforçou o valor dos espaços de diálogo como ferramentas de educação ambiental transformadora.

Nesse processo, portanto, os acadêmicos se posicionaram de forma a facilitar os diálogos para que a comunidade ali representada refletisse com base nos seus conhecimentos e assim, eles perceberem o território urbano de seu município por meio da ótica ecoturística.

Para os professores orientadores do IFS, curso de Gestão de Turismo, a iniciativa extensionista com ações junto a comunidades enriqueceu a formação dos acadêmicos, entretanto, reforçaram a necessidade de planejar ações não só a curto, mas a médio e longo prazo na mesma comunidade.

Portanto, os espaços de discussões abertos na comunidade, possibilitaram a ampliação da visão dos acadêmicos, moradores e do trade para com a llha, a Reserva e a cidade de Itaporanga. Assim a troca de informações foi fundamental para se observar esses ambientes com um olhar turístico.

\section{Referências Bibliográficas}

BOO, E. O planejamento ecoturístico para áreas protegidas. In: LINDBERG, K.; HAWKINS, D. E. Ecoturismo: um guia para planejamento e gestão. 4.ed. São Paulo: Editora Senac São Paulo, 2002.

BRAGHINI, C. R.; PICANÇO, C. S (Orientadores). Projeto: Re-Conhecer Pedra Bonita. IFS, 2009.

BRANDON, K. Etapas básicas para incentivar a participação local em projetos de turismo voltado para natureza. In: LINDBERG, K.; HAWKINS, D. E. Ecoturismo: um Guia para Planejamento e Gestão. 4.ed. São Paulo: Editora Senac São Paulo, 2002.

CURADO, F. F. Gestão Participativa para o Desenvolvimento da Comunidade Mem de Sá, Itaporanga D'Ajuda-SE. Embrapa Tabuleiros Costeiros, 2007.

CEBALLOS-LASCURÁIN, H. O ecoturismo como um fenômeno mundial. In: LINDBERG, K.; HAWKINS, D. E. Ecoturismo: um Guia para Planejamento e Gestão. 4.ed. São Paulo: Editora Senac São Paulo, 2002.

EMBRAPA. Reserva do Caju. Disponível em: <http://www.cpatc.embrapa.br/caju>. Acesso em: 18 ago. 2009. 
Espaços de diálogo na comunidade para o Ecoturismo: a llha Mem de Sá, Itaporanga D’ajuda (SE).

FARIA, A. A. C.; FERREIRA NETO, P. S. Ferramentas do diálogo: qualificando o uso das técnicas do DRP: diagnóstico rural participativo.Brasília: MMA; IEB, 2006.

LOUREIRO, C. F. B. Educar, participar e transformar em educação ambiental. Revista Brasileira de Educação Ambiental. Brasília, n.0, p.13-20, 2004.

MENDONÇA, R.; NEIMAN, Z. Ecoturismo: Discurso, Desejo e Realidade. In: NEIMAN, Z. (Org). Meio Ambiente, Educação e Ecoturismo. Barueri: Manole, 2002.

OMT. Organização Mundial de Turismo. Guia de desenvolvimento do turismo sustentável. Porto Alegre: Bookman, 2003.

SEPLAN-SE/SUPES/GIGEC. Secretaria de Estado do Planejamento de Sergipe. Superintendência de Estudos e Pesquisas. Gerência de Informações Geográficas e Cartográficas. VEJA SERGIPE: Visualizador da base cartográfica dos municípios litorâneos. DVD-ROM. Aracaju, 2008.

SILVA, V. P.; CARDOSO, M. P. A. Oficina 4 - Danças Populares Brasileiras. Disponível em: <http://www.ufscar.br/ defnh/spqmh/coloq07/oficinas/danca.pdf>. Acesso em: 18 ago. 2009

WESTERN, D. Definindo o ecoturismo. In: LINDBERG, K.; HAWKINS, D. E. Ecoturismo: um guia para planejamento e gestão. 4.ed. São Paulo: Editora Senac São Paulo, 2002.

Cleberton Santos Souza: Instituto Federal de Educação, Ciência e Tecnologia - SE. Email: cleberton@ig.com.br

Link para o currículo Lattes: http://lattes.cnpq.br/3407751853130115

Claudio Roberto Braghini: Instituto Federal de Educação, Ciência e Tecnologia - SE Email: claudio.braghini@ifs.edu.br

Link para o currículo Lattes:http://lattes.cnpq.br/6345985821227558

Layslene Ferreira de Araújo: Instituto Federal de Educação, Ciência e Tecnologia - SE Email: leys_ferreira@hotmail.com

Link para o currículo Lattes: http://lattes.cnpq.br/6500764083357402

Data de submissão: 30 de outubro de 2009.

Data do aceite: 12 de março de 2010. 